\title{
Studies on fatty-acid-binding proteins
}

\section{The purification of rat liver fatty-acid-binding protein and the role of cysteine-69 in fatty acid binding}

\author{
David C. WILTON \\ Department of Biochemistry, School of Biochemical and Physiological Sciences, University of Southampton, \\ Bassett Crescent East, Southampton SO9 3TU, U.K.
}

\begin{abstract}
1. A new, simple and high-yield procedure is described for the purification of hepatic fatty-acid-binding protein from rat liver using naphthylaminodecyl-agarose as an affinity column. 2. Cysteine-69 is shown to react slowly, but quantitatively, with 5,5'-dithiobis-(2-nitrobenzoic acid) (DTNB), indicating that the thiol group is free, but may be buried within the protein. 3. Fatty acids do not affect the DTNB reactivity of this cysteine residue; however, cysteine reactivity is enhanced in the presence of haem and oleoyl-CoA. 4. Fattyacid-binding protein that has been modified with DTNB is still able to bind the fluorescent fatty acid 11(dansylamino)undecanoic acid, indicating that cysteine-69 may be remote from the fatty-acid-binding site.
\end{abstract}

\section{INTRODUCTION}

Rat liver fatty-acid-binding protein (FABP) is an abundant $14000-M_{\mathrm{r}}$ cytosolic protein that has a high affinity for long-chain fatty acids and their CoA esters, as well as for a number of non-polar organic anions (Glatz \& Veerkamp, 1985; Sweetser et al., 1987). Although the precise physiological function of this protein remains obscure (Sweetser et al., 1987), the recent identification of this protein as the target for certain chemical carcinogens in the liver (Ketterer et al., 1976; Bassuk et al., 1987) and the apparent relationship of the protein to hepatocyte cell division highlights the potential importance of the protein to liver-cell function. A complete understanding of the function of this protein will require detailed knowledge about the number of binding sites on the protein, the amino acid residues that constitute these binding sites and the possible conformational changes that ensue on ligand binding. This approach will be greatly facilitated if it is possible to prepare easily large quantities of pure protein.

We have recently described in outline the preparation and use of a novel affinity column for FABP which involved linking a dansyl group to $\omega$-aminodecyl-agarose (Sheridan \& Wilton, 1988). The ligand now attached to the agarose matrix closely resembled the hydrophobic fatty acid probe 11-(dansylamino)undecanoic acid (DAUDA), which we have used previously to investigate liver FABP (Wilkinson \& Wilton, 1986, 1987). Although this affinity column was effective in purifying liver FABP in a single step after initial fractionation of liver cytosol by gel filtration, the column showed long-term deterioration, probably due to the photo-instability of the immobilized fluorescent dansyl ligand. In the present paper I describe the complete purification of FABP using the more stable medium naphthoylaminodecyl-agarose (NAG), and have used this material to investigate the role of the single cysteine residue in liver FABP (Cys-69) in ligand binding.

\section{MATERIALS AND METHODS}

\section{Chemicals}

DAUDA was obtained from Molecular Probes, Junction City, OR, U.S.A. $\omega$-Aminodecyl-agarose was obtained from Sigma Chemical Co., Poole, Dorset, U.K. Naphthoyl chloride was obtained from Aldrich Chemical Co., Gillingham, Dorset, U.K.

\section{Preparation of NAG}

$\omega$-Aminodecyl-agarose $(50 \mathrm{ml} ; 6.15 \mu \mathrm{mol}$ of $1,10-$ diaminodecane $/ \mathrm{ml}$ of gel) was suspended in satd. $\mathrm{NaHCO}_{3}(50 \mathrm{ml})$. Naphthoyl chloride $(0.1 \mathrm{ml})$ in acetone $(50 \mathrm{ml})$ was added with stirring and the suspension was stirred overnight in the dark at room temperature. A column was prepared with the material, which was washed extensively with water and then $0.1 \mathrm{M}$-potassium phosphate buffer, pH 7.4.

\section{Purification of FABP from rat liver}

The rat liver cytosolic fraction was prepared as previously described (Wilkinson \& Wilton, 1986). The cytosol from two $200 \mathrm{~g}$ female Wistar albino rats was further purified by the following procedure. The cytosol $(34 \mathrm{ml})$ was applied to a column of Sephadex G-75 $(4.5 \mathrm{~cm} \times 65 \mathrm{~cm})$, equilibrated with $0.1 \mathrm{M}$-potassium phosphate buffer, $\mathrm{pH} \mathrm{7.4,} \mathrm{and} \mathrm{the} \mathrm{eluted} \mathrm{fractions} \mathrm{were}$ assayed for FABP activity as previously described (Wilkinson \& Wilton, 1986). The pooled FABP fractions were concentrated by ultrafiltration (Amicon YM5 membrane) and applied to the NAG column. The NAG column was eluted with the $0.1 \mathrm{M}$-potassium phosphate buffer, $\mathrm{pH} \mathrm{7.4,} \mathrm{to} \mathrm{remove} \mathrm{unbound} \mathrm{protein} \mathrm{and} \mathrm{then,}$ after changing to $0.075 \mathrm{M}$-potassium phosphate buffer, pH 6.0, the FABP was selectively eluted by using $25 \%$ (v/v) ethanol in this buffer as described by Kawashima $e t$ al. (1983). The eluted material was concentrated by ultrafiltration and dialysed into $0.01 \mathrm{M}$-potassium phos-

Abbreviations used: FABP, fatty-acid-binding protein; DAUDA, 11-(dansylamino)undecanoic acid; NAG, naphthoylaminodecyl-agarose; DTNB, 5,5'-dithiobis-(2-nitrobenzoic acid); TNB, 5-thio-2-nitrobenzoic acid. 
phate buffer, $\mathrm{pH}$ 7.4. This material may be stored for several days on ice or for several months at $-30^{\circ} \mathrm{C}$ with negligible loss of activity. Homogeneity of the final preparation was confirmed by the appearance of a single protein band on SDS/polyacrylamide-gel electrophoresis (15\% acrylamide gels; Laemmli, 1970) and a single peak on analysis by gel-permeation h.p.l.c. The NAG column was regenerated by washing with $1 \%$ SDS in $25 \%$ ethanol $(300 \mathrm{ml})$ at room temperature, followed by water (2 litres), and finally the column was re-equilibrated with $0.1 \mathrm{M}$-potassium phosphate, $\mathrm{pH} 7.4$ at $5^{\circ} \mathrm{C}$. The NAG column has a binding capacity of about $1 \mathrm{mg}$ of FABP per $\mathrm{ml}$ of bed volume and represents about $1-2 \%$ of the theoretical binding capacity of the column for hepatic FABP.

H.p.l.c. analysis, fluorescence measurements and protein determination

These methods have been described previously (Wilkinson \& Wilton, 1986).

\section{Measurement of DTNB-reactivity of hepatic FABP}

The assay system for DTNB-reactivity $(1 \mathrm{ml})$ contained $0.1 \mathrm{M}$-borate, pH $9.0(0.3 \mathrm{ml}), 0.01 \mathrm{M}$-potassium phosphate buffer, $\mathrm{pH} 7.4(0.5 \mathrm{ml})$, FABP in $0.01 \mathrm{M}$ potassium phosphate buffer $(0.1 \mathrm{ml})$ and DTNB $(4 \mathrm{mg} / \mathrm{ml})$ in $0.05 \mathrm{M}$-potassium phosphate buffer, $\mathrm{pH} 7.2$ $(0.1 \mathrm{ml})$. The reaction was monitored at $412 \mathrm{~nm}$ and an absorption coefficient of $13600 \mathrm{l}^{-1} \cdot \mathrm{mol}^{-1} \cdot \mathrm{cm}^{-1}$ was used for calculating the amount (mol) of TNB anion released. The final $\mathrm{pH}$ of the assay was 8.6.

\section{RESULTS AND DISCUSSION}

\section{Purification of hepatic FABP using NAG affinity chromatography}

The purification of hepatic FABP by gel filtration and NAG affinity chromatography is described in the Materials and methods section and is summarized in Table 1 . The final preparation was essentially pure after SDS/polyacrylamide-gel electrophoresis (Fig. 1) and gave a single peak after gel-permeation h.p.l.c. analysis (Fig. 2). No other bands were observed in the $14000-M_{r}$ region when smaller amounts of the pure FABP were subjected to SDS/polyacrylamide-gel electrophoresis (results not shown). The method of purification initially involved delipidation of the cytosol with di-isopropyl ether (Ochner et al., 1982; Sheridan \& Wilton, 1988), since it was presumed that removal of endogenous fatty acids would facilitate the binding of FABP to the NAG column. However, it would now appear that delipidation of the cytosol is not necessary, presumably due to competitive displacement of any bound fatty acid with the very large excess of immobilized ligand. It should be noted that the purification of FABP with oleic acid-agarose did not require prior delipidation (Vincent \& Muller-Eberhard, 1985).

The advantages of the NAG affinity column described above as compared with the oleic acid-agarose used previously for the routine purification of FABP (Kawashima et al., 1983; Vincent \& Muller-Eberhard, $1985)$ are: (1) the NAG is more conveniently prepared than oleic acid-agarose and (2) the hydrophobic interaction between NAG and FABP is weaker than that between oleic acid-agarose and FABP and requires $25 \%$ ethanol rather than $50 \%$ ethanol for complete elution of FABP from the column. We have also prepared hexadecylaminodecyl-agarose by using the methods described above using hexadecylsulphonyl chloride. This material also bound FABP, but elution required $50 \%$ ethanol, and the recovery of active protein was low when compared with that obtained when the NAG column was used (D. C. Wilton, unpublished work). In summary, the procedure described in here for the purification of FABP is both convenient and provides a high yield of the protein that will allow detailed studies of protein-ligand interactions.

\section{Reaction of hepatic FABP with DTNB}

Hepatic FABP contains a single thiol group (Cys-69) that has not been investigated in terms of its possible role in fatty acid binding. The reactivity of a cysteine residues with DTNB remains the most convenient method of assessing the importance of this residue in protein function. The kinetics of the reaction of DTNB with FABP under different conditions is shown in Table 2, and demonstrates a stoichiometric release of TNB anion. The reaction is slow, indicating that this thiol group may be buried within the protein and not readily accessible to external reagents. When the single thiol group of bovine serum albumin is titrated with DTNB under the same conditions, the reaction rate is about 15 -fold higher (Table 2), whereas the reaction of DTNB with this single cysteine residue is considerably less than stoichiometric. This observation is attributed to the presence of a mixed disulphide of albumin with glutathione and other thiols (Fuller-Noel \& Hunter, 1972).

In the case of albumin, the rate of reaction with DTNB

Table 1. Purification of FABP from rat liver cytosol

Cytosol was prepared from the livers of two female Wistar albino rats.

\begin{tabular}{|c|c|c|c|c|c|c|}
\hline \multirow[b]{2}{*}{ Fraction } & \multirow[b]{2}{*}{$\begin{array}{l}\text { Volume } \\
\text { (ml) }\end{array}$} & \multirow[b]{2}{*}{$\begin{array}{l}\text { Protein } \\
(\mathrm{mg} / \mathrm{ml})\end{array}$} & \multicolumn{2}{|c|}{ Fluorescence } & \multirow[b]{2}{*}{$\begin{array}{l}\text { Purification } \\
\text { (fold) }\end{array}$} & \multirow[b]{2}{*}{$\begin{array}{l}\text { Yield } \\
(\%)\end{array}$} \\
\hline & & & $\begin{array}{c}\text { Total (in } \\
\text { arbitary } \\
\text { units) }\end{array}$ & $\begin{array}{l}\text { Specific } \\
\text { (per mg of } \\
\text { protein) }\end{array}$ & & \\
\hline Cytosol & 34 & 54 & 1487 & 0.8 & 1 & 100 \\
\hline G-75 column fraction & 40 & 2.11 & 460 & 5.75 & 7.19 & 31 \\
\hline NAG column fraction & 5.5 & 2.25 & 378 & 30.7 & 38.4 & 25 \\
\hline
\end{tabular}




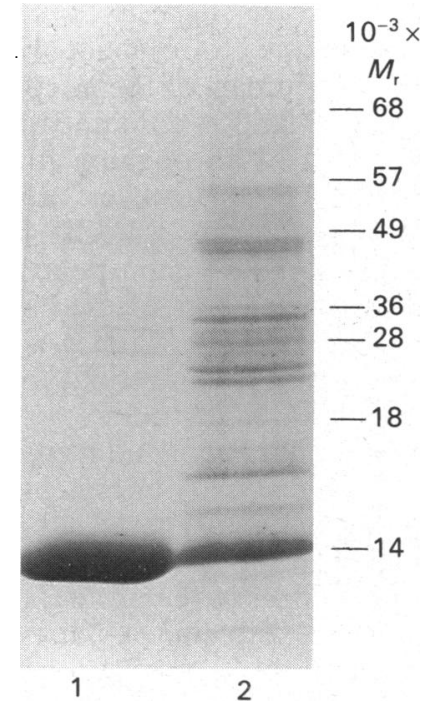

Fig. 1. SDS/polyacrylamide-gel electrophoresis of fractions during purification of FABP from rat liver cytosol

Protein samples were subjected to electrophoresis on an SDS $/ 15 \%(w / v)$-polyacrylamide gel. Track 1, pure FABP $(56 \mu \mathrm{g})$ eluted from the NAG column; track 2, FABP fraction from the Sephadex G-75 column containing $10 \mu \mathrm{g}$ of protein. Marker $\boldsymbol{M}_{\mathrm{r}}$ values are shown.

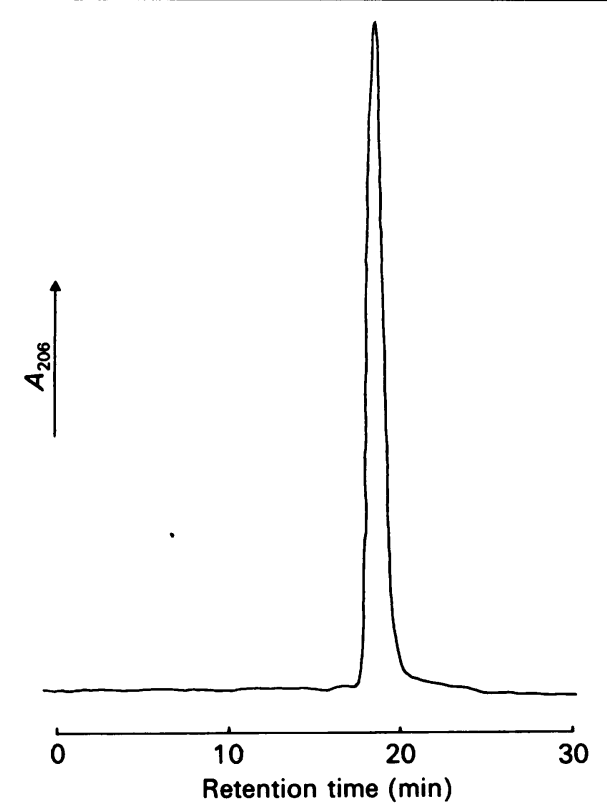

Fig. 2. H.p.l.c. analysis of rat liver FABP purified by NAG affinity chromatography

A $0.2 \mathrm{ml}$ portion of FABP $(0.45 \mathrm{mg} / \mathrm{ml})$ was run on a TSK-G $200 \mathrm{SW}$ column $(7.5 \mathrm{~mm} \times 600 \mathrm{~mm})$. The column was eluted with $0.1 \mathrm{M}$-potassium phosphate buffer, $\mathrm{pH} 7.4$, run at $1 \mathrm{ml} / \mathrm{min}$.

was affected by fatty acids (Takabayashi et al., 1983), but this is not the case with FABP (Table 2) using fatty acid concentrations that will essentially saturate the fatty acid-binding site of this protein. The very low solubility of long-chain fatty acids precludes the use of higher concentrations of fatty acids in the assay. There are two other physiologically relevant ligands for hepatic FABP, namely fatty acyl-CoA and haem. In the case of haem,

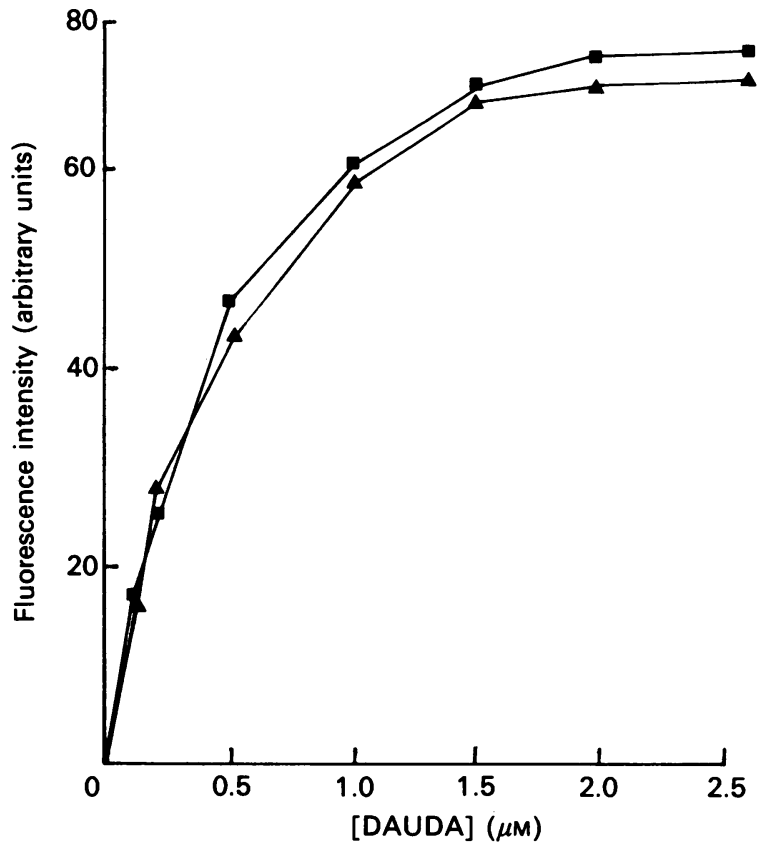

Fig. 3. Binding properties of native and DTNB-modified rat liver FABP

FABP $(0.45 \mathrm{mg} / \mathrm{ml})$ was incubated in the presence or absence of DTNB until the DTNB reaction was complete. FABP was purified from the reaction mixture and the control by h.p.l.c., and purified samples $(0.64 \mathrm{nmol})$ were titrated with DAUDA. The fluorescence enhancement at $500 \mathrm{~nm}$ due to binding of the probe to FABP was determined. Each curve is the average for three titrations. $\boldsymbol{\square}$, Native FABP; $\boldsymbol{\Delta}$, DTNB-modified FABP.

this ligand increased the reactivity of FABP about 9-fold, suggesting that the more bulky haem may produce conformational changes in the protein resulting in increased exposure of the cysteine to external reagents. An effect of haem on the antibody-binding properties of rat liver FABP has already been noted (Vincent \& Muller-Eberhard, 1985). The stoichiometry of reaction of DTNB with FABP in the presence of haem is significantly greater than $1: 1$. However, the assay is complicated not only by the high levels of absorbance of haem at $412 \mathrm{~nm}$, but in particular because of the increased absorbance of haem on binding to FABP. The difference in absorption coefficient between bound and free haem at $411 \mathrm{~nm}$ is $42500 \mathrm{l}^{-1} \cdot \mathrm{mol}^{-1} \cdot \mathrm{cm}^{-1}$ (Tipping et al., 1976). High absorbance precludes the use of concentrations of haem in the assay above $0.05 \mathrm{~mm}$.

Although it is quite clear that hepatic FABP binds fatty acyl-CoAs, whether this binding is at the same site at which fatty acids bind or at a different site, or is of higher or lower affinity than fatty acid binding, remains to be clarified. The reactivity of DTNB with FABP is not significantly affected by the presence of stoichiometric amounts of oleoyl-CoA; however, higher concentrations of this ligand did enhance the reactivity of cysteine- 69 . This increase in rate with increasing acyl-CoA concentration may be due to a non-specific detergent effect of the ligand, since acyl-CoAs are reported to have a critical micelle concentration of the order of $0.01-0.1 \mathrm{mM}$ (Brecher, 1983). However, a second, lower-affinity, binding site on FABP for fatty acyl-CoA, and also for haem, cannot be ruled out at this stage and requires further examination. 
Table 2. Effect of ligands on the DTNB-reactivity of hepatic FABP

The rate and extent of reaction of DTNB with FABP was monitored at $412 \mathrm{~nm}$ and quantified by using an absorption coefficient of $13600 \mathrm{I}^{-1} \cdot \mathrm{mol}^{-1} \cdot \mathrm{cm}^{-1}$. For comparison, the reactivity of DTNB with bovine serum albumin (BSA; $0.028 \mathrm{mM}$ ) is shown. The concentration of FABP used in the assay for the data shown was $0.008 \mathrm{~mm}$. All values are the averages of at least three independent determinations. N.D., not determined.

\begin{tabular}{|c|c|c|}
\hline Assay conditions & $\begin{array}{l}\text { Rate of DTNB } \\
\text { reaction (nmol/ } \\
\text { min per nmol } \\
\text { of protein) }\end{array}$ & $\begin{array}{l}\text { Extent of DTNB } \\
\text { reaction (mol } \\
\text { of DTNB } \\
\text { reduced/ } \\
\text { mol of } \\
\text { protein) }\end{array}$ \\
\hline FABP (control) & 0.11 & 1.05 \\
\hline$+0.02 \mathrm{~mm}$-Oleic acid & 0.11 & 1.04 \\
\hline +0.02 nM-DAUDA & 0.12 & 1.03 \\
\hline $\begin{array}{l}+ \text { Oleoyl-CoA } \\
0.01 \mathrm{mM} \\
0.02 \mathrm{mM} \\
0.05 \mathrm{mM} \\
0.10 \mathrm{mM} \\
0.2 \mathrm{mM}\end{array}$ & $\begin{array}{l}0.12 \\
0.19 \\
0.33 \\
0.65 \\
1.20\end{array}$ & $\begin{array}{l}0.98 \\
1.14 \\
1.19 \\
1.07 \\
1.07\end{array}$ \\
\hline $\begin{array}{l}\text { + Haem } \\
0.01 \mathrm{mM} \\
0.02 \mathrm{mM} \\
0.05 \mathrm{mM}\end{array}$ & $\begin{array}{l}0.27 \\
0.59 \\
0.99\end{array}$ & $\begin{array}{r}1.38 \\
1.43 \\
>2\end{array}$ \\
\hline FABP + 4 M-urea & N.D. & 1.01 \\
\hline BSA control & 1.61 & 0.54 \\
\hline
\end{tabular}

Ability of DTNB-modified FABP to bind fatty acids and haem

The reaction of DTNB with FABP was monitored to completion and then the reaction mixture was purified by gel-permeation h.p.l.c. A control incubation not containing DTNB was similarly purified at this time. Spectral analysis of the DTNB-modified FABP clearly showed the presence of a peak at $330 \mathrm{~nm}$ characteristic of the TNB group, and using an absorption coefficient of $8900 \mathrm{l}^{-1} \cdot \mathrm{mol}^{-1} \cdot \mathrm{cm}^{-1}$ at $330 \mathrm{~nm}$ (Riddles et al., 1983), this absorbance corresponded to a stoichiometric incorporation of TNB into the protein. When control FABP samples and DTNB-modified samples of FABP were assayed for their capacity to bind the fluorescent fatty acid probe DAUDA, both protein samples behaved in a very similar manner in terms of their affinity for the probe and the stoichiometry of binding (Fig. 3). These results clearly establish that cysteine-69 is not involved in fatty acid binding and may be remote from the fattyacid-binding site. In addition, the direct addition of haem to an incubation mixture after complete reaction of FABP with DTNB resulted in a similar increase in absorbance at $405 \mathrm{~nm}$ (as a result of protein-bound haem) as was observed on addition of haem to unmodified FABP. Thus cysteine-69 is also not involved in the binding of the more bulky haem ligand at the single highaffinity site for haem on hepatic FABP (Vincent \& Muller-Eberhard, 1985).

Although the crystal structure for hepatic FABP is not available, the structure for the intestinal form of FABP has recently been solved (Sacchettini et al., 1988). Exam- ination of the structure suggests that the region of this protein corresponding to cysteine-69. in the hepatic protein does not form part of the fatty-acid-binding site, but is adjacent to it and is contained within a $\beta$-strand that may form part of an opening to the hydrophobic interior of the FABP. However, although both the hepatic and intestinal forms of FABP belong to a family of low-molecular-mass non-polar ligand-binding proteins, these two members of the family do not show major identity (Sweetser et al., 1987), so extrapolation of the crystal structure of the intestinal form to the hepatic form must be done with caution.

The observation that haem and oleoyl-CoA are able to increase the DTNB reactivity of cysteine-69 suggests that this cysteine residue may be a suitable site for the attachement of reporter groups to investigate possible conformational changes in the protein on ligand binding. Proteins with single cysteine residues are particularly attractive models for this type of approach, as exemplified by studies with calmodulin (Mills et al., 1988; Yuan \& Huag, 1988) and the Escherichia coli transcription termination factor Rho (Seifried et al., 1988). This approach now needs to be applied to FABP in an attempt to obtain further insight into the precise physiological function of this protein in the liver.

Financial support from the Wessex Medical Trust and the SmithKline (1982) Foundation is gratefully acknowledged, as is the assistance of Miss M. Sheridan and Miss A. Goff.

\section{REFERENCES}

Bassuk, J. A., Tsichlis, P. N. \& Sorof, S. (1987) Proc. Natl. Acad. Sci. U.S.A. 84, 7547-7551

Brecher, P. (1983) Mol. Cell. Biochem. 57, 3-15

Fuller-Noel, J. K. \& Hunter, M. J. (1972) J. Biol. Chem. 247, 7391-7406

Glatz, J. F. C. \& Veerkamp, J. H. (1985) Int. J. Biochem. 17, 13-22

Kawashima, Y., Nakagawa, S., Tachibana, Y. \& Kozuka, H. (1983) Biochim. Biophys. Acta 754, 21-27

Ketterer, B., Tipping, E., Hackney, J. F. \& Beale, D. (1976) Biochem. J. 115, 511-521

Laemmli, U. K. (1970) Nature (London) 227, 680-685

Mills, J. S., Walsh, M. P., Nemcek, K. \& Johnson, J. D. (1988) Biochemistry 27, 991-996

Ochner, R. K., Manning, J. A. \& Kane, J. P. (1982) J. Biol. Chem. 257, 7872-7878

Riddles, P. W., Blakeley, R. L. \& Zerner, B. (1983) Methods Enzymol. 91, 49-60

Sacchettini, J. C., Gordon, J. I. \& Banaszak, L. J. (1988) J. Biol. Chem. 263, 5815-1819

Seifried, S. E., Wang, Y. \& von Hippel, P. H. (1988) J. Biol. Chem. 263, 13511-13514

Sheridan, M. \& Wilton, D. C. (1988) Biochem. Soc. Trans. 16, 719

Sweetser, D. A., Heuckeroth, R. O. \& Gordon, J. I. (1987) Annu. Rev. Nutr. 7, 337-359

Takabayashi, K., Imada, T., Saito, Y. \& Inada, Y. (1983) Eur. J. Biochem. 136, 291-295

Tipping, E., Ketterer, B., Christodoulides, L. \& Enderby, G. (1976) Biochem. J. 157, 461-467

Vincent, S. H. \& Muller-Eberhard, U. (1985) J. Biol. Chem. 260, 14521-14528

Wilkinson, T. C. I. \& Wilton, D. C. (1986) Biochem. J. 238, 419-424

Wilkinson, T. C. I. \& Wilton, D. C. (1987) Biochem. J. 247, 485-488

Yuan, S. \& Huag, A. (1988) Eur. J. Biochem. 175, 119-124 